\title{
CLASSIFICAÇÃO DO ESTADO DO RIO GRANDE DO SUL SEGUNDO O SISTEMA DE ZO- NAS DE VIDA DE HOLDRIDGE
}

\author{
HOLDRIDGE LIFE ZONE CLASSIFICATION FOR THE SOUTHERN BRAZILIAN STATE 'RIO \\ GRANDE DO SUL'
}

\author{
Diego Augusto Valério ${ }^{1}$ Andressa Tres $^{2}$ Alexandre França Tetto ${ }^{3}$ Ronaldo Viana Soares ${ }^{4}$ William Tho- \\ maz Wendling ${ }^{3}$
}

\section{RESUMO}

O clima é a síntese de elementos meteorológicos observados durante um longo período de tempo e possui estreita relação com a vegetação. A classificação climática de Holdridge define zonas de vida representativas para as diferentes regiões da Terra, que refletem a conjuntura destes elementos meteorológicos. Este trabalho objetivou a classificação do estado do Rio Grande do Sul segundo este sistema, visando comparar com a classificação climática de Köppen, bem como as fitogeografias do estado. Com base em uma série histórica não contínua mínima de 25 anos, de 1950 a 1990, de dados pluviométricos e de temperatura, associados às variáveis de latitude e altitude, foi possível calcular e determinar as zonas de vida individualmente para os 496 municípios do estado. Oito zonas de vida foram encontradas, das quais se destacaram: floresta úmida temperada basal (74,0\%); floresta muito úmida/floresta úmida temperada basal $(13,8 \%)$; e floresta úmida/floresta muito úmida temperada basal $(8,0 \%)$. A relação entre Holdridge e Köppen apresentou correspondência acima de $90 \%$ em sete das oito zonas de vida encontradas (87,5\% do território do estado), predominantemente com o tipo climático $\mathrm{Cfa}$ (clima temperado, com chuva o ano todo e verão quente). Regiões de Estepe e Savana-estépica obtiveram 100\% de correspondência com as zonas de vida floresta muito úmida temperada basal e com as respectivas transições com floresta úmida temperada basal. O sistema de zonas de vida de Holdridge mostrou-se uma importante ferramenta para o zoneamento agrossilvicultural do estado, uma vez que houve uma interação satisfatória quando comparado com o sistema de classificação climática de Köppen e com algumas fitogeografias.

Palavras-chave: classificação climática; biotemperatura; fitogeografia.

\begin{abstract}
Climate is the synthesis of meteorological elements observed during a long time and it has a close relationship with vegetation. Holdridge climatic classification defines representative life zones by different regions on Earth, which explain all these meteorological elements. Therefore, this study has aimed a classification of Rio Grande do Sul state according to Holdridge life zone system by seeking to compare with Köppen climate classification system and vegetation that occurs in the state. That was possible to calculate and determine the life zones for the 496 cities of the state by a minimal sequence of not continuous 25 years of rain and temperature data from 1950 to 1990 . Thereby eight life zones were found for the state, which ones has detached: temperate moist forest $(74,0 \%)$; temperate wet forest $/$ moist forest $(13,8 \%)$; temperate moist forest/wet forest (8,0\%). Holdridge and Köppen relation has shown correlation above $90 \%$ in seven of the eight life zones found $(87,5 \%$ of the state territory), predominantly with climatic type Cfa (humid

1 Graduando em Engenharia Florestal, Universidade Federal do Paraná, Departamento de Engenharia Florestal, Av. Prefeito Lothário Meissner, 632, CEP 80210-170,Curitiba (PR), Brasil. diego.valerio.sbs@gmail.com

2 Engenheira Florestal, MSc., Doutoranda do Programa de Pós-Graduação em Ciências Florestais, Departamento de Ciências Florestais, Universidade Federal do Paraná, Av. Prefeito Lothário Meissner, 632, CEP 80210-170, Curitiba (PR), Brasil. tres.andressa@gmail.com

3 Engenheiro Florestal, Dr., Professor do Departamento de Ciências Florestais, Universidade Federal do Paraná, Av. Prefeito Lothário Meissner, 632, CEP 80210-170, Curitiba (PR), Brasil. tetto@ufpr.br / wendling@ufpr.br

4 Engenheiro Florestal, PhD., Professor do Departamento de Ciências Florestais, Universidade Federal do Paraná, Av. Prefeito Lothário Meissner, 632, CEP 80210-170, Curitiba (PR). rvsoares@ufpr.br
\end{abstract}

Recebido para publicação em 14/08/2017 e aceito em 25/09/2017

Ci. Fl., v. 28, n. 4, out. - dez., 2018 
subtropical, without dry season, with hot summer). Steppe and Steppe-Savanna regions got correlation of $100 \%$ with life zone temperate wet forest and its respective transition zones with temperate moist forest. Holdridge life zones system has shown an important tool for agriculture and forestry zoning in this state once there was a satisfied interaction while comparing with Köppen climate classification system and some phytogeographies.

Keywords: climate classification; biotemperature; phytogeography.

\section{INTRODUÇÃO}

O clima é caracterizado pela variação de um conjunto de elementos meteorológicos (SOARES; BATISTA; TETTO, 2015) que, sob determinado intervalo de tempo, influenciam significativamente na caracterização de fatores físicos e biológicos, tais como solo e vegetação de uma dada região.

Sob esta perspectiva, o uso de sistemas de classificação climática é importante no âmbito da caracterização do clima de uma região, além de auxiliar na compreensão das variações do clima no mundo (AYOADE, 2003). De acordo com Tres et al. (2016), dentre os sistemas de classificação mais utilizados no Brasil estão o de Köppen (1936), Thornthwaite (1948) e Holdridge (1966).

Não obstante, Nóbrega (2010) retrata que muitos dos sistemas de classificação climática podem ser falhos e imprecisos quanto a sua aplicabilidade, dependendo do conjunto de variáveis que são utilizadas para a definição das zonas climáticas e da forma com que estas variáveis são tratadas. Portanto, a escolha de um sistema de classificação climática dependerá, basicamente, das particularidades intrínsecas à área e ao objetivo do estudo (ROSSATO, 2011).

Alguns trabalhos de classificação climática já foram realizados para o estado do Rio Grande do Sul baseados em séries históricas de dados meteorológicos. Kuinchtner e Buriol (2001) conduziram estudos que visaram à classificação climática do estado de acordo com os sistemas de Köppen e Thornthwaite, encontrando os tipos climáticos Superúmido $(\mathrm{A})$ e Úmido $\left(\mathrm{B}_{4}, \mathrm{~B}_{3}\right.$ e $\left.\mathrm{B}_{2}\right)$ segundo a classificação de Thornthwaite. Para o sistema de classificação climática de Köppen (1936), os autores determinaram a ocorrência dos tipos climáticos Cfa e Cfb. Por sua vez, Buriol et al. (2007) buscaram caracterizar o clima do estado de acordo com o diagrama climático de Walter e Lieth (1967), encontrando nove zonas climáticas. De modo geral, os estudos realizados por Kuinchtner e Buriol (2001) e por Buriol et al. (2007) demonstram uma tipologia climática relativamente heterogênea para o Rio Grande do Sul, levantando novas expectativas quanto à necessidade da caracterização do estado por meio de outros sistemas, tais como o de Holdridge (1966).

O sistema de classificação de Holdridge, por sua vez, baseia-se na premissa da biotemperatura, definida por ele como sendo um intervalo de temperatura de 0 a $30^{\circ} \mathrm{C}$ (HOLDRIDGE, 2000). Segundo Soares, Batista e Tetto (2015), tal intervalo compreende a temperatura em que efetivamente ocorre o desenvolvimento das plantas. Ometto (1981) corrobora genericamente sobre estes limites de temperatura sob uma perspectiva fisiológica, isto é, quando as temperaturas atingem patamares abaixo deste limite mínimo de temperatura, a atividade fisiológica da planta a condiciona a uma regulação metabólica mínima vital, enquanto em temperaturas acima do limite máximo, as taxas respiratórias aumentam de tal modo que o montante de produção das reações fotossintéticas é todo consumido no processo de respiração, refletindo em fotossíntese líquida igual à zero. Portanto, em primeira análise, regiões em que há temperaturas médias mensais além destes limites mínimo e máximo em grande parte dos meses ao decorrer de um ciclo anual, contribuem para a regulação de produção vegetal. Entretanto, trata-se de um intervalo genérico, no qual está inclusa a maioria das plantas, cada espécie particularmente correspondendo a uma biotemperatura média ideal, não significando, portanto, que todas as plantas seguem a mesma tendência fisiológica dentro destes limites.

Associando a biotemperatura aos pisos altitudinais e regiões latitudinais existentes em uma região de estudo, Holdridge (2000) definiu as unidades do sistema como "zonas de vida". Com a classificação de Holdridge, torna-se prática a compreensão da relação entre clima e a tipologia vegetal, uma vez que o sistema relaciona os gradientes de altitude e de latitude na busca de tentar explicar a predominância fitogeográfica de uma dada região.

À luz das observações supracitadas, uma classificação climática que sugere uma determinada tipologia vegetal na região, dá subsídios para outros estudos que envolvam, por exemplo, o zoneamento 
agrossilvicultural do estado do Rio Grande do Sul. Portando, o objetivo deste estudo foi realizar a classificação climática das zonas de vida de Holdridge para o Rio Grande do Sul e compará-las com a cobertura vegetal e com o sistema de classificação climática de Köppen.

\section{MATERIAL E MÉTODO}

\section{Caracterização da área de estudo}

Rio Grande do Sul é o estado mais meridional do Brasil e está localizado na região sul com área de 281.748,538 km², cujos limites dos eixos latitudinal e longitudinal são representados pelas coordenadas geográficas $27^{\circ} 04^{\prime} 56^{\prime \prime} ; 33^{\circ} 45^{\prime} 04^{\prime \prime} \mathrm{S}$ e $49^{\circ} 41^{\prime} 28^{\prime \prime} ; 57^{\circ} 38^{\prime} 36^{\prime \prime} \mathrm{W}$, respectivamente (IBGE, 2011).

O estado é coberto pelos biomas Mata Atlântica (63\%) e Pampa (37\%) (IBGE, 2004), subdivididos pelas unidades fitogeográficas da Floresta Ombrófila Mista, Floresta Ombrófila Densa, Floresta Estacional Decidual, Floresta Estacional Semidecidual, Estepe e Savana-Estépica, além de uma extensa Área de Formações Pioneiras (Figura 1).

De acordo com Alvares et al. (2014), o estado possui as seguintes classes climáticas segundo Köppen: Cfa (clima temperado, com chuva o ano todo e verão quente) e $\mathrm{Cfb}$ (clima temperado, com chuva o ano todo e verão morno), ilustradas na Figura 2. Desta forma, concordando com os estudos realizados por Kuinchtner e Buriol (2001).

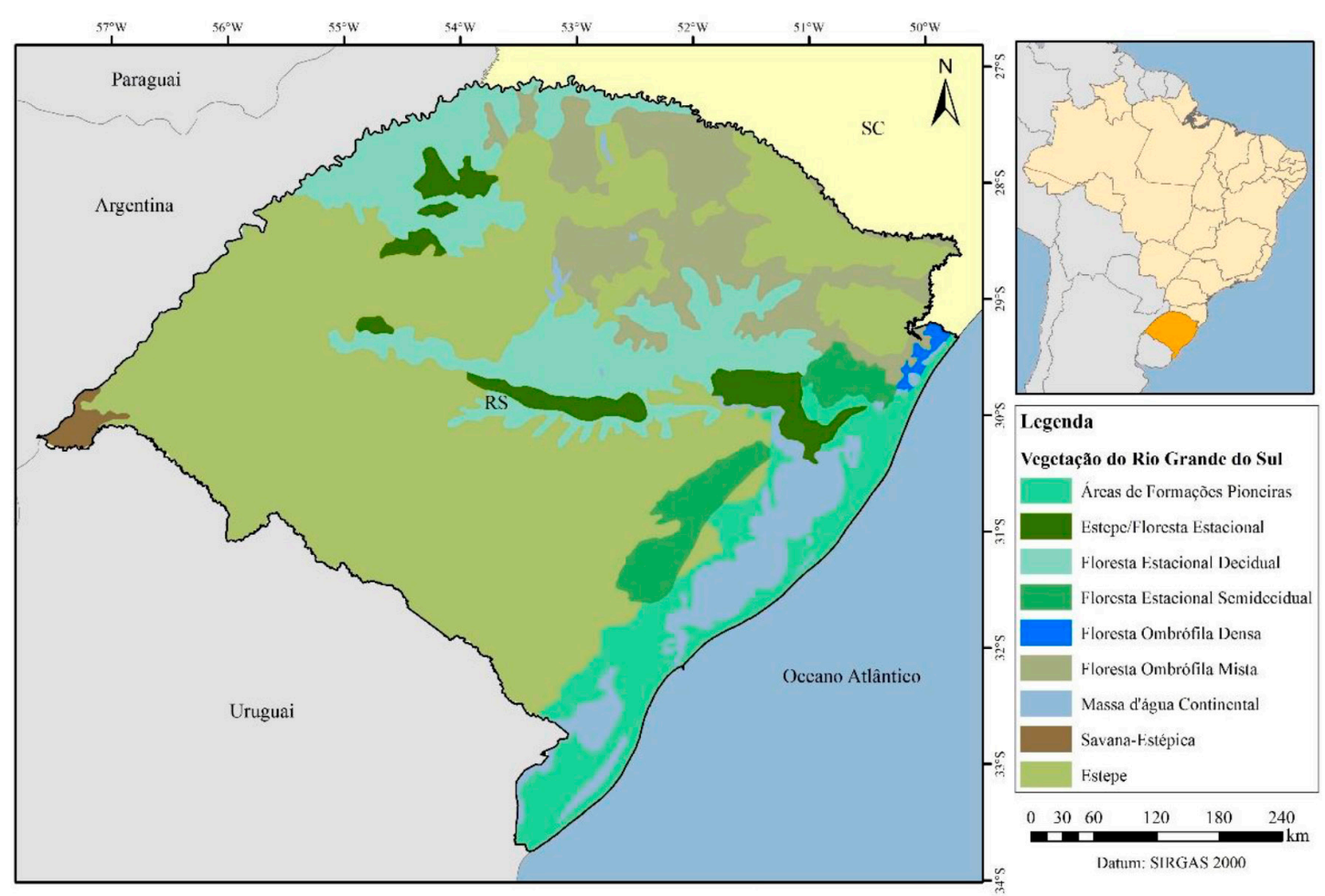

FIGURA 1: Mapa fitogeográfico do Rio Grande do Sul (Fonte: IBGE (2006), adaptado pelos autores, 2017). FIGURE 1: Phytogeography map of Rio Grande do Sul state. 


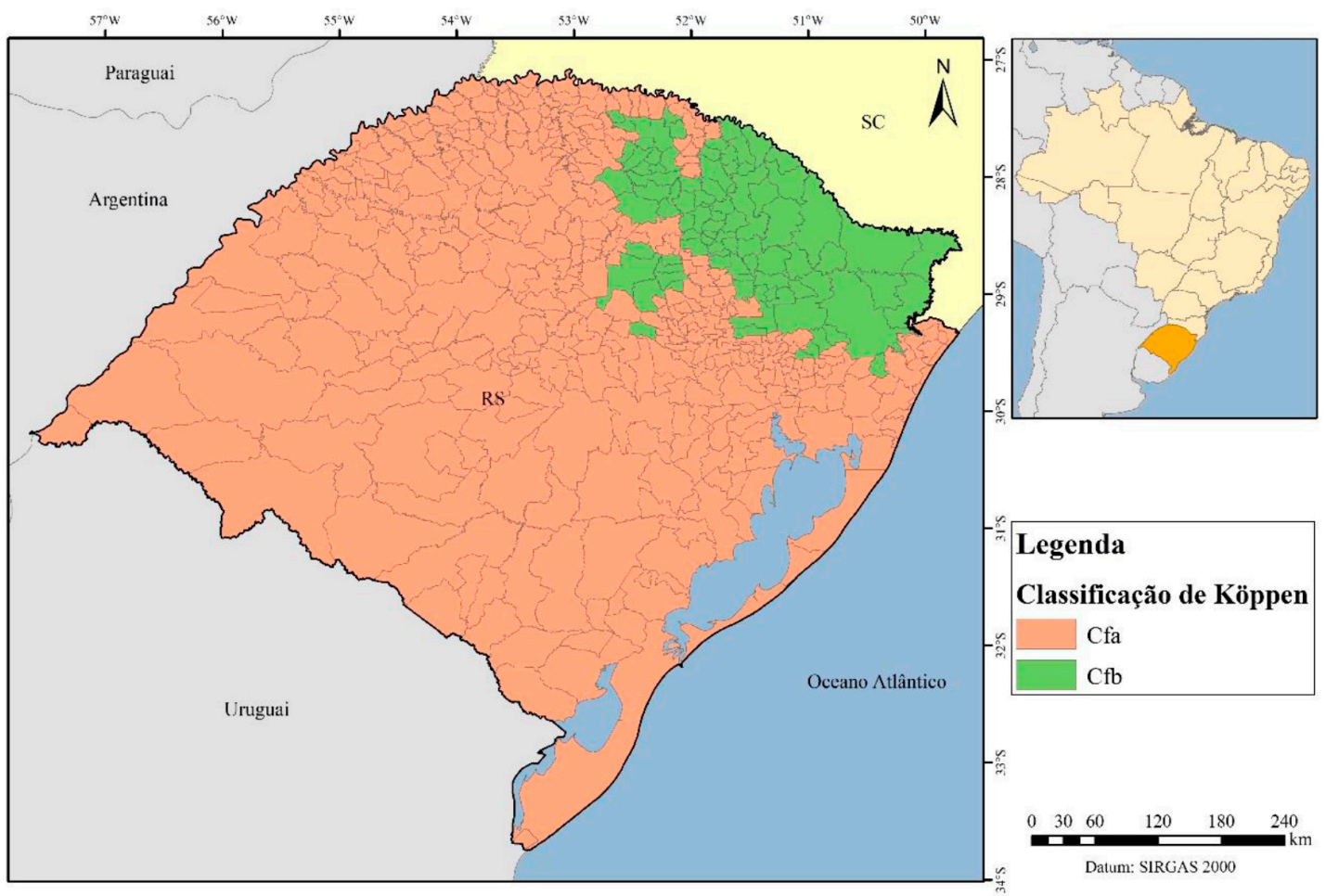

FIGURA 2: Mapa de classificação climática de Köppen para o Rio Grande do Sul (Fonte: Alvares et al. (2014), adaptado pelos autores, 2017).

FIGURE 2: Köppen climate classification map for Rio Grande do Sul state.

\section{Obtenção dos dados meteorológicos}

Os dados meteorológicos foram obtidos por um estudo realizado por Alvares et al. (2014), que classificaram o Brasil de acordo com o sistema de classificação climática de Köppen. Este estudo foi subsidiado por 2.950 estações meteorológicas com registros de mais de 25 anos de dados pluviométricos não contínuos de 1950 a 1990. Ademais, para temperatura média mensal, considerando o mesmo período, Alvares et al. (2013) selecionaram 2.400 estações meteorológicas. Este conjunto de dados permitiu aos autores extrapolar a temperatura e precipitação para o Brasil, baseando-se em estimativas calculadas por meio de geoestatística. Posteriormente, os dados foram compilados, gerenciados e processados em um Sistema de Informações Geográficas (SIG), no qual passaram por modelagem multivariada. Os dados de temperatura e precipitação médias obtidos por Alvares et al. (2014), os quais foram atribuídos individualmente para cada município rio-grandense, subsidiaram os cálculos de biotemperatura média mensal, permitindo estabelecer as zonas de vida de Holdridge para todo o estado.

\section{Cálculo da biotemperatura}

Sendo a biotemperatura o intervalo de temperatura em que ocorre o efetivo crescimento das plantas $\left(0\right.$ a $\left.30^{\circ} \mathrm{C}\right)$, o sistema de classificação de Holdridge (2000) estabelece que todas as temperaturas médias mensais abaixo de $0^{\circ} \mathrm{C}$ devem ser eliminadas e as acima de $24^{\circ} \mathrm{C}$ devem ser corrigidas para que temperaturas acima de $30^{\circ} \mathrm{C}$, as quais eventualmente tenham ocorrido durante o período, sejam sistematicamente 
desconsideradas da média mensal. Esta correção é feita por intermédio da seguinte equação:

$$
T_{\text {cor }}=T-\left[\frac{3 l}{100}(T-24)^{2}\right]
$$

Em que: $T_{c o r}=$ biotemperatura do mês corrigida; $T=$ temperatura média mensal; $l=$ latitude do local.

O somatório das biotemperaturas corrigidas dividida por doze (meses) equivale à biotemperatura média anual, calculada a partir da seguinte fórmula:

$$
T_{\text {bio }}=\frac{\sum_{i=1}^{12} T_{\text {cor }}>0{ }^{\circ} \mathrm{C}}{12}
$$

Em que: $T_{b i o}=$ biotemperatura média anual do local.

No diagrama de classificação de zonas de vida (Figura 3), insere-se a biotemperatura média anual em conjunto com a precipitação média anual, determinando as zonas de vida que são delimitadas pelos hexágonos. Cada hexágono possui uma área referente ao núcleo da zona de vida e seis triângulos adjacentes que formam as zonas de transição.

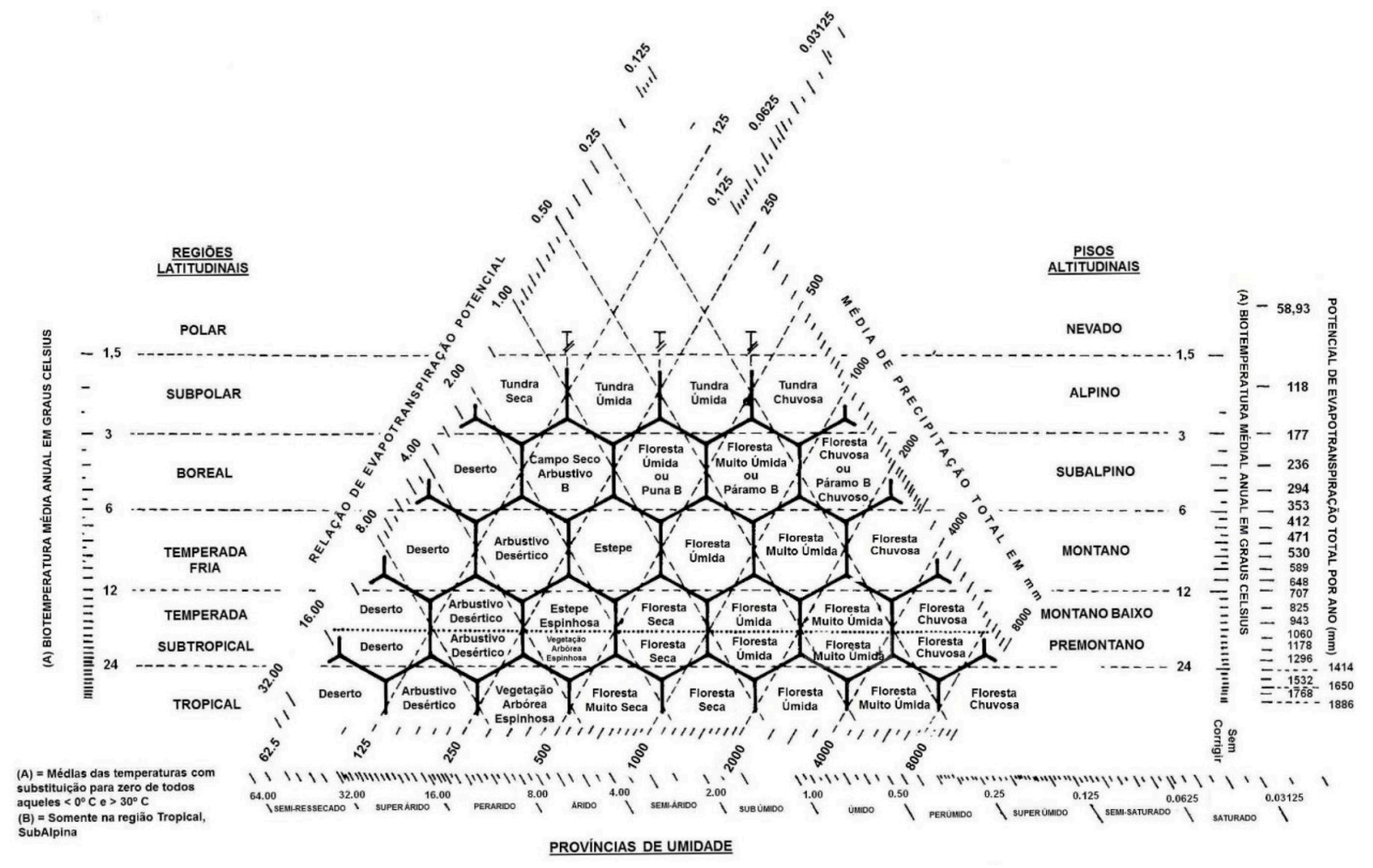

FIGURA 3: Diagrama de classificação das zonas de vida de Holdridge (Fonte: Holdridge (2000), adaptado por Soares, Batista e Tetto, 2015).

FIGURE 3: Diagram of Holdridge life zone classifications.

A classificação ainda necessita da determinação da região latitudinal (Tabela 1) e do piso altitudinal (Figura 4) para a conclusão da classificação. 
TABELA 1: Extensões aproximadas das regiões latitudinais em graus segundo Holdridge.

TABLE 1: Close estimate range of the latitudinal regions in degrees according to Holdridge.

\begin{tabular}{cc}
\hline Regiões Latitudinais & Classes de Latitude \\
\hline Polar & $90^{\circ} 00^{\prime}-67^{\circ} 22^{\prime}$ \\
Subpolar & $67^{\circ} 22^{\prime}-64^{\circ} 45^{\prime}$ \\
Boreal & $64^{\circ} 45^{\prime}-56^{\circ} 30^{\prime}$ \\
Temperada frio & $56^{\circ} 30^{\prime}-42^{\circ} 00^{\prime}$ \\
Temperada & $42^{\circ} 00^{\prime}-27^{\circ} 30^{\prime}$ \\
Subtropical & $27^{\circ} 30^{\prime}-13^{\circ} 00^{\prime}$ \\
Tropical & $13^{\circ} 00^{\prime}-00^{\circ} 00^{\prime}$ \\
\hline
\end{tabular}

FONTE: Holdridge (2000), adaptado por Soares, Batista e Tetto (2015).

O diagrama de pisos altitudinais, por sua vez, representa as biotemperaturas em função dos gradientes de altitude e latitude e a sua respectiva equivalência nos diferentes ambientes da Terra, considerando um gradiente adiabático médio de $-0,6^{\circ} \mathrm{C}$ para cada $100 \mathrm{~m}$ de elevação na correção das biotemperaturas médias anuais para o nível do mar.

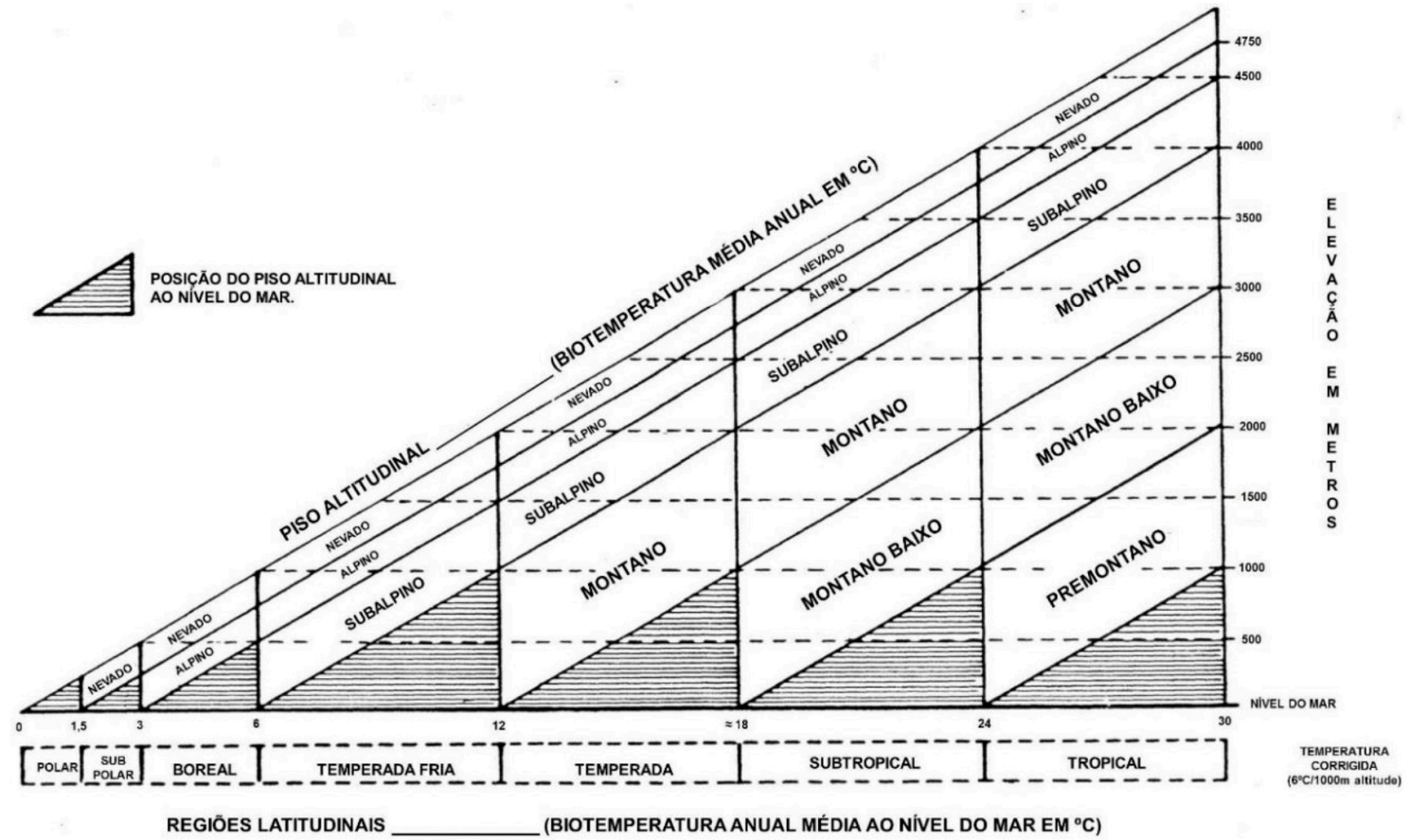

FIGURA 4: Diagrama dos pisos altitudinais do sistema de Holdridge (Fonte: Soares, Batista e Tetto (2015)).

FIGURE 4: Diagram of altitudinal level grounds from Holdridge system.

\section{Análise dos dados}

Através de processamento realizado no software FoxPro dos dados de temperatura média mensal e precipitação média mensal, foram calculadas as biotemperaturas em nível municipal, cujas etapas são sintetizadas pelo fluxograma a seguir (Figura 5). Os resultados obtidos permitiram atribuir a cada município rio-grandense uma zona de vida, gerando assim o mapa estadual da classificação de Holdridge. Posteriormente, realizaram-se análises espaciais de arquivos matriciais, contendo informações sobre 
cobertura vegetal e da classificação de Köppen, em sobreposição ao mapa de classificação de Holdridge para o Rio Grande do Sul, utilizando um software SIG. Esta análise buscou verificar a existência de afinidade entre valores atribuídos por cada pixel de um arquivo matricial (raster) ao rol de atributos associados a um arquivo vetorial, dando assim um percentual de recorrência espacial.

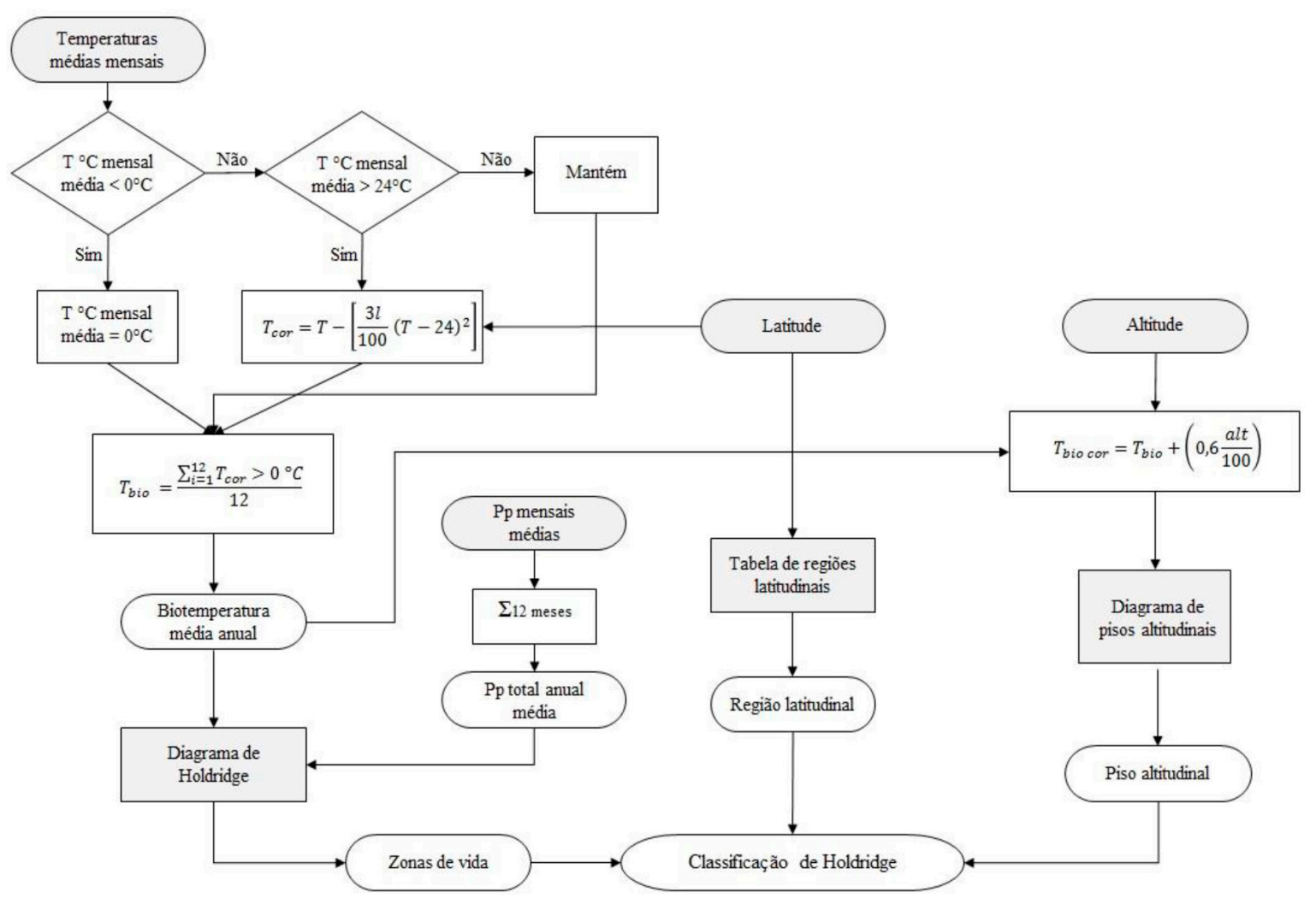

FIGURA 5: Fluxograma dos processos realizados pelo software Foxpro.

FIGURE 5: Flow chart of the procedures accomplished by Foxpro.

\section{RESULTADOS E DISCUSSÃO}

\section{Biotemperaturas}

$\mathrm{O}$ estado apresentou uma amplitude de biotemperaturas de aproximadamente $6^{\circ} \mathrm{C}$, que foi subdivida em seis classes de amplitude de $1^{\circ} \mathrm{C}$ cada. No mapa de biotemperaturas (Figura 6), nota-se a ocorrência de biotemperaturas de 17,8 a $19,8^{\circ} \mathrm{C}$ em uma ampla região do estado, abrangendo as regiões oeste, central e litoral. Ficaram evidenciados alguns picos acima de $18,8^{\circ} \mathrm{C}$ associados a estas regiões, principalmente no extremo norte da Planície Litorânea, na Depressão Central e no Vale do Rio Uruguai. Por outro lado, menores valores foram observados no extremo nordeste do estado dentro da região do Planalto Meridional, nos municípios de São José dos Ausentes e Cambará do Sul, onde ocorrem as maiores altitudes. A partir destes municípios, um transecto no sentido leste-oeste mostra a tendência nos aumentos da biotemperatura em função da diminuição da altitude, uma vez que a latitude permanece constante.

$\mathrm{Na}$ região do Escudo Rio-grandense, na qual ocorrem altitudes próximas a $200 \mathrm{~m}$, verificaram-se biotemperaturas variando de 14,8 a $16,8^{\circ} \mathrm{C}$. Esta região experimenta pisos altitudinais equivalentes a algumas regiões do oeste do Planalto Meridional e Vale do Rio Uruguai, contudo, apresentando menores biotemperaturas. Isto se deve, possivelmente, pela influência latitudinal em que se encontram estas duas regiões, visto que há uma diferença de aproximadamente $3^{\circ}$ de latitude entre ambas. A região nordeste do estado apresentou mudanças abruptas de biotemperaturas em relação ao seu entorno. Esta região está inserida 
entre as localidades da Serra do Umbú e Serra do Pinto, nas quais amplitudes de 2,9 e de $4,2^{\circ} \mathrm{C}$ foram verificadas, respectivamente. Amplitudes térmicas como estas são comumente encontradas em regiões de serra e em regiões montanhosas, devido ao gradiente adiabático médio de $-0,6^{\circ} \mathrm{C}$ para cada $100 \mathrm{~m}$ na elevação, uma vez que estes ambientes apresentam declividade acentuada e pequena variação em latitude e longitude.

Em toda a faixa litorânea foi possível verificar uma queda progressiva da biotemperatura seguindo o aumento do gradiente latitudinal. Uma vez que esta faixa litorânea possui altitudes constantes próximas a $0 \mathrm{~m}$, a variação de pisos altitudinais permaneceu isolada, permitindo que a latitude atuasse pontualmente na definição dos resultados. Sob este aspecto, no extremo norte da região litorânea, observou-se a ocorrência das maiores biotemperaturas, decrescendo no sentido sul de forma regular. Tal que as classes de biotemperaturas de 16,8 a 17,8 e 17,8 a $18,8^{\circ} \mathrm{C}$ seguiram uma relação inversamente proporcional de $-1^{\circ} \mathrm{C}$ para cada $1,5^{\circ}$ de latitude, aproximadamente. Ainda, imediatamente abaixo, nos municípios de Chuí e Santa Vitória do Palmar, obtiveram-se valores de 14,8 a $15,8^{\circ} \mathrm{C}$, evidenciando esta mesma tendência.

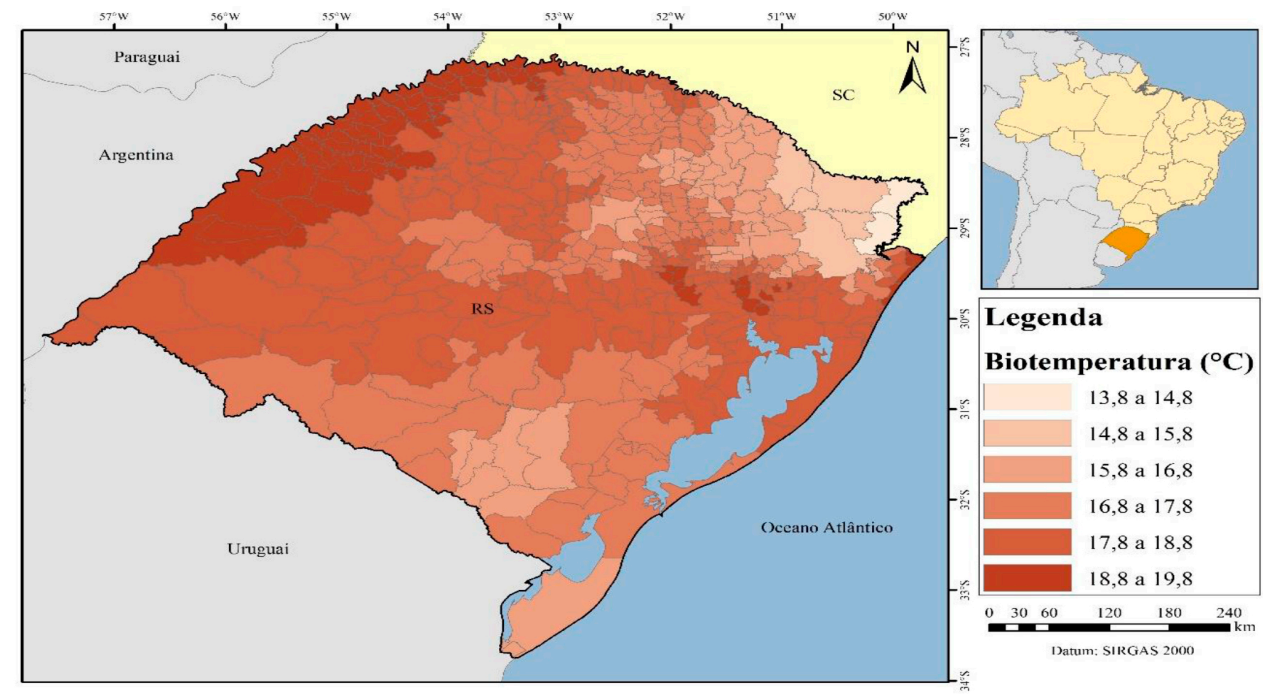

FIGURA 6: Mapa de biotemperaturas médias anuais do Rio Grande do Sul.

FIGURE 6: Map of the yearly average biotemperatures in Rio Grande do Sul state.

\section{Classificação de zonas de vida de Holdridge}

Segundo o sistema de classificação climática de Holdridge (2000), foi constatada a ocorrência de oito zonas de vida no Rio Grande do Sul, sendo que quatro delas são zonas de transição. A forma como estão distribuídas estas zonas de vida, no estado, pode ser observada na Figura 7 e seus respectivos percentuais de ocorrência estão descritos na Tabela 2.

TABELA 2: Percentual de ocorrência das zonas de vida no Rio Grande do Sul.

TABLE 2: Percentage of occurrence in life zones in Rio Grande do Sul state.

\begin{tabular}{lc}
\hline Classificação de Holdridge & $\%$ \\
\hline Floresta muito úmida temperada basal & 1,7 \\
Floresta muito úmida/floresta úmida subtropical basal & 1,8 \\
Floresta muito úmida/floresta úmida temperada basal & 13,8 \\
Floresta muito úmida/floresta úmida subtropical montana baixa & 0,3 \\
Floresta úmida/floresta muito úmida temperada basal & 8,0 \\
\hline
\end{tabular}

Continuação... 
TABELA 2: Continua...

TABLE 2 Continued...

\begin{tabular}{lc}
\hline Classificação de Holdridge & $\%$ \\
\hline Floresta úmida temperada basal & 74,0 \\
Floresta úmida subtropical basal & 0,3 \\
Floresta úmida subtropical montana baixa & 0,1 \\
\hline
\end{tabular}

Os resultados obtidos mostraram que $74 \%$ do estado está inserido na zona de vida floresta úmida temperada basal, sendo que as zonas de transição entre floresta úmida e floresta muito úmida temperada compõem $21,8 \%$ do total, enquanto $1,7 \%$ são compostos pela floresta muito úmida temperada basal que agrega três manchas isoladas no Planalto Meridional sob os municípios de São Francisco de Paula, Canela, Campestre da Serra, São Marcos e Barão de Cotegibe. As zonas de vida floresta úmida subtropical basal e montana baixa somam $0,4 \%$ da área total do estado e outros $2,1 \%$ são formados pelas zonas de transição entre floresta muito úmida e floresta úmida dentro da região latitudinal subtropical. Logo, o clima temperado visivelmente predomina no estado, cujas zonas de vida e as devidas zonas de transição abarcam 97,5\% da sua área total. O clima subtropical, por sua vez, abrange somente uma região no extremo norte, que coincide com o paralelo $27^{\circ} 30^{\prime}$. Os limites do eixo latitudinal $27^{\circ} 04^{\prime} 56^{\prime \prime}$ e $33^{\circ} 45^{\prime} 04^{\prime \prime}$ S no estado (IBGE, 2011) explicam as regiões latitudinais subtropical e temperada encontradas.

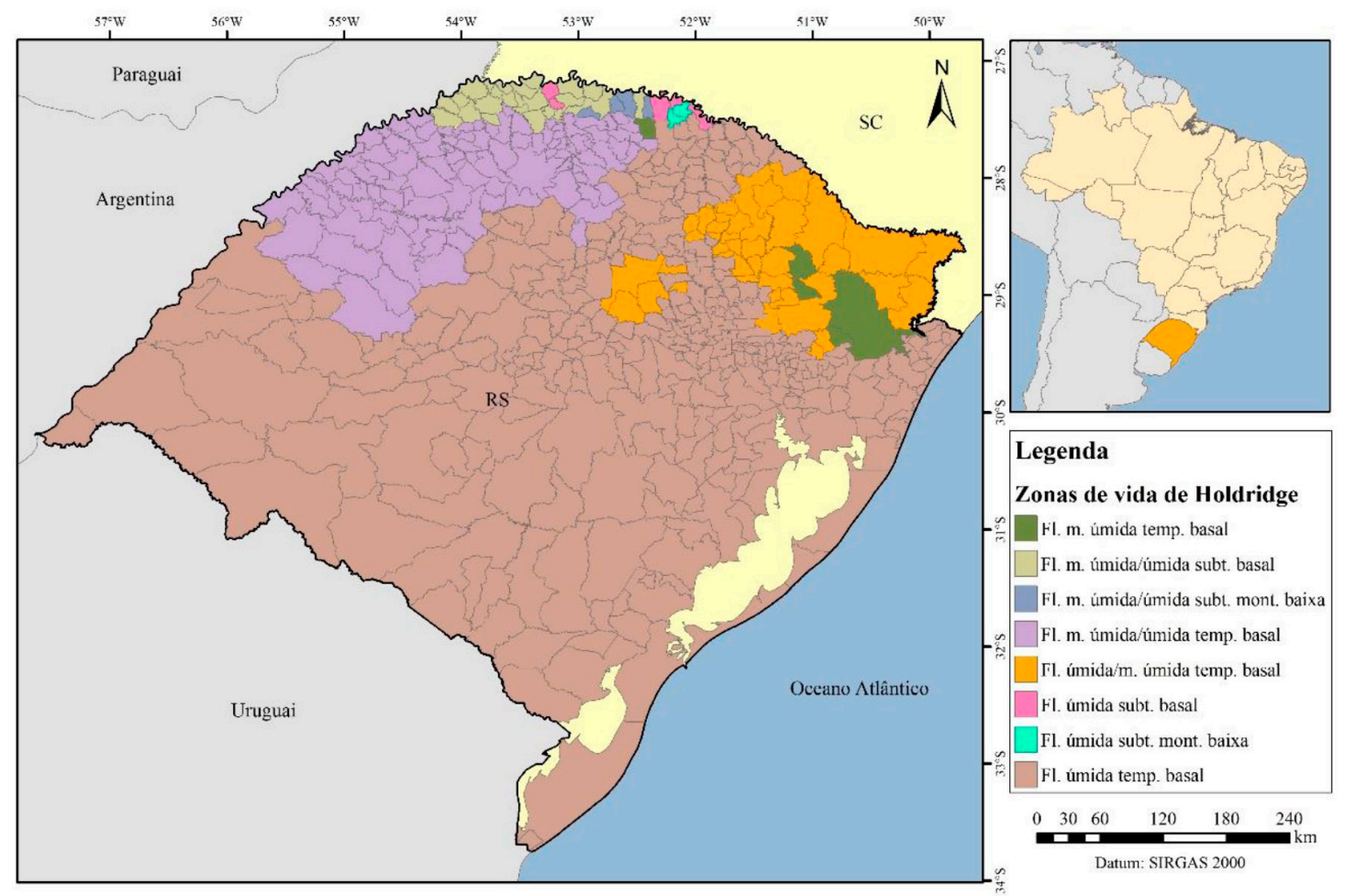

Em que: Fl. = floresta; $\mathrm{m}$. = muito; subt. = subtropical; temp. = temperada.

FIGURA 7: Mapa das zonas de vida de Holdridge para o Rio Grande do Sul.

FIGURE 7: Map of Holdridge life zones for Rio Grande do Sul state.

O índice pluviométrico anual médio determinado por Britto (2004), entre as diferentes regiões do Rio Grande do Sul, corrobora as zonas de vida encontradas no estado. De acordo com Britto, Barletta, Mendonça (2008), existe uma clara tendência no aumento do nível pluviométrico no sentido sul-norte, sendo que ao norte da latitude $30^{\circ} \mathrm{S}$ os níveis médios de chuva anual ultrapassam os $1.500 \mathrm{~mm}$, enquanto ao sul são inferiores. Sotério, Pedrollo e Andriotti (2005) enfatizam a ocorrência dos maiores níveis pluviométri- 
cos nas regiões do Planalto Meridional e do Alto Vale do Uruguai com índices de 2.130 e $1.900 \mathrm{~mm}$ médios anuais, respectivamente, seguido das regiões mais altas do Escudo Rio-grandense com índices superiores a $1.600 \mathrm{~mm}$. De acordo com os mesmos autores, na fronteira com o Uruguai, os níveis pluviométricos são inferiores a $1.500 \mathrm{~mm}$, mas no litoral sul encontram-se os menores índices, cujos valores não ultrapassam os $1.400 \mathrm{~mm}$ anuais. Os níveis pluviométricos encontrados por Álvares et al. (2013), atribuídos neste processo de classificação de Holdridge para o estado, evidenciam o pressuposto acima, uma vez que os ambientes de floresta muito úmida e as transições para floresta úmida estão predominantemente alocados na metade norte do estado nas regiões do Planalto Meridional e do Alto Vale do Uruguai, enquanto os ambientes de floresta úmida abarcam a metade sul do estado e uma faixa quase contínua no extremo norte entremeada dos ambientes de floresta muito úmida.

Tres (2016) encontrou, para os estados de Santa Catarina e Paraná, zonas de vida predominantemente compostas por florestas úmidas e muito úmidas e suas respectivas zonas de transição. Excetuando uma região ao norte do Paraná, que apresentou a ocorrência da zona de vida transitória de floresta úmida/ floresta seca subtropical basal, verificou-se uma consonância entre o Rio Grande do Sul e a região sul do Brasil. Isto se deve a um regime de chuvas típico ao longo do ano que, embora diferenciado dentro do estado, com mínimas próximas a $1.300 \mathrm{~mm}$ nas regiões mais secas, apresenta uma distribuição relativamente equilibrada ao longo de todo ano (RIO GRANDE DO SUL, 2013). Sobretudo, o Rio Grande do Sul é o estado do sul com mais zonas de vida classificadas como temperadas, uma vez que grande parte de seu território está abaixo do paralelo $27^{\circ} 30^{\prime}$. De acordo com Tres (2016), a maior zona de vida da região sul é a floresta úmida temperada basal, ocupando $40,66 \%$ da área total desta região, sendo que a maior fatia está inserida no Rio Grande do Sul. Os três estados compartilham da maioria das zonas de vida, excetuando-se pelas zonas: floresta muito úmida/floresta úmida temperada basal e floresta úmida temperada basal, encontradas apenas no Rio Grande do Sul; floresta muito úmida subtropical basal e floresta muito úmida subtropical montana baixa, exclusivas de Santa Catarina e para o Paraná, floresta úmida/floresta muito úmida subtropical basal e floresta úmida/floresta seca subtropical basal.

Segundo Becker e Nunes (2012), o estado possui altitudes que chegam a $1.300 \mathrm{~m}$, na porção nordeste da região do Planalto Meridional, decrescendo no sentido leste-oeste até atingir patamares de $700 \mathrm{~m}$, enquanto na região da Depressão Central ocorrem altitudes situadas entre 100 e $200 \mathrm{~m}$. O mesmo ocorre na região do Escudo, em que apenas alguns lugares apresentam altitudes que ultrapassam $300 \mathrm{~m}$. Na Planície Litorânea e na região do Baixo Vale do Rio Uruguai, Miranda (2005) menciona a ocorrência de menores altitudes, variando de 0 a $90 \mathrm{~m}$. Portanto, observa-se que o estado apresenta altitudes diversificadas, mas com topografia variando de forma gradativa e, em sua maioria, abaixo de $1.000 \mathrm{~m}$. Isto refletiu no enquadramento do estado quanto aos pisos altitudinais basais, excetuando-se quatro municípios que apresentaram a classe montano baixo e estão localizados no Planalto Meridional: Severiano de Almeida, Três Arroios, Erval Grande e Faxinalzinho, cujas altitudes médias são de aproximadamente 591, 648, 610 e 609 m, respectivamente. Não obstante, verificaram-se outras altitudes maiores no estado, como a de São José dos Ausentes, mas não obtiveram a combinação de fatores (latitudinal, altitudinal e biotemperatura) para o devido enquadramento fora do piso basal, uma vez que estão inseridos na região temperada do estado.

\section{Comparação entre os sistemas de classificação de Holdridge e Köppen}

Os devidos percentuais de correspondência no Rio Grande do Sul entre os dois sistemas de classificação são apresentados na Tabela 3. 
TABELA 3: Percentual de correspondência entre os sistemas de classificação de Holdridge e Köppen.

TABLE 3: Overlap ratio between Holdridge and Köppen classification systems.

\begin{tabular}{ccc}
\hline & \multicolumn{2}{c}{ Classificação de Köppen } \\
\cline { 2 - 3 } Classificação de Holdridge & $\mathrm{Cfa}$ & $\mathrm{Cfb}$ \\
\cline { 2 - 3 } & $\%$ & $\%$ \\
\hline Floresta úmida subtropical basal & 100,0 & 0,0 \\
Floresta muito úmida floresta úmida subtropical basal & 100,0 & 0,0 \\
Floresta muito úmida/floresta úmida subtropical montana baixa & 100,0 & 0,0 \\
Floresta muito úmida temperada basal & 0,0 & 100,0 \\
Floresta úmida/floresta muito úmida temperada basal & 3,0 & 97,0 \\
Floresta muito úmida floresta úmida temperada basal & 98,4 & 1,6 \\
Floresta úmida temperada basal & 94,6 & 5,4 \\
Floresta úmida subtropical montana baixa & 52,1 & 47,9 \\
\hline
\end{tabular}

Os resultados indicam quatro zonas de vida com $100 \%$ de correspondência associadas a alguma zona climática de Köppen e três que estão acima de $90 \%$. O tipo climático Cfa agregou três zonas de vida e zonas de transição com $100 \%$ e duas com correspondência acima de $90 \%$. Esta tendência provavelmente se explica pelo fato de $86,3 \%$ do estado ser composto por este tipo climático. Além disso, verificou-se que o tipo climático $\mathrm{Cfa}$ está ligado principalmente à classe latitudinal subtropical, excetuando-se duas ocorrências em latitudes temperadas. Por sua vez, o tipo climático $\mathrm{Cfb}$, correspondendo a $13,7 \%$ da área do estado, abarcou duas zonas de vida e transições com correspondência acima de $90 \%$, sendo que uma delas atingiu $100 \%$. Verificou-se, sobretudo, que estas zonas de vida estão inseridas na classe latitudinal temperada. A zona de vida floresta úmida subtropical montano baixo ficou inserida em uma região de transição entre as zonas climáticas $\mathrm{Cfa}$ e $\mathrm{Cfb}$, com correspondência de 52,1 e 47,9\%, respectivamente. Logo, o resultado permite inferir que $87,5 \%$ das zonas de vida de Holdridge obtiveram correspondência alta com alguma zona climática de Köppen.

\section{Comparação das zonas de vida com a vegetação}

O Rio Grande do Sul possui uma fitogeografia bastante diversificada, passando por densas florestas arbóreas traduzidas entre a Floresta Ombrófila Mista (FOM), Floresta Ombrófila Densa (FOD), além de Florestas Estacionais Decíduas (FED) e Semidecíduas (FES) ao norte, nordeste e na região central. Verificou-se ainda a ocorrência de uma mancha de Savana-Estépica (SAV-E), isolada a sudoeste do estado. Sobretudo, grande parte do território está subdividido em vastas regiões de Estepe (EST), que formam o bioma Pampa. De acordo com IBGE (2012), esta fisionomia caracteriza as regiões da campanha gaúcha com uma vegetação herbácea contínua. Verificou-se ainda, amplas Áreas de Formações Pioneiras (AFP) em toda a região costeira.

Quando comparadas à classificação de Holdridge para o estado, notou-se que três regiões fitogeográficas (FOD, AFP e SAV-E) estão inseridas unicamente na floresta úmida temperada basal, com 100\% de correspondência. Entretanto, não se pode inferir que exista uma correlação entre esta zona de vida e estas classes de vegetação, pois se trata de fitogeografias com baixa recorrência no estado, não formando mais do que uma única mancha isolada. Por outro lado, todas as outras regiões fitogeográficas formam um conjunto de manchas distribuídas de maneira quase contínua. Isto reflete em uma distribuição bastante ampla de algumas unidades fitogeográficas, como aconteceu para a FED e FOM, as quais ocorreram sob todas as zonas de vida. A transição de Estepe e Floresta Estacional (EST/FE) obteve 100\% de ocorrência dentro da zona floresta úmida temperada basal e entre a transição com a floresta muito úmida temperada basal. O mesmo ocorreu com a tipologia EST, em que mais de $3 / 4$ ocorreram na floresta úmida temperada basal, seguido de 
$1,8 \%$ na floresta muito úmida temperada basal e $19,5 \%$ nas regiões de transição destas duas zonas de vida (Tabela 4).

TABELA 4: Percentual de ocorrência entre as fitogeografias do Rio Grande do Sul e as zonas de vida de Holdridge. TABLE 4: Occurrence ratio between Rio Grande do Sul phytogeography and Holdridge life zones.

\begin{tabular}{ccccccccc}
\hline \multirow{2}{\text{Tipologia}}{$\begin{array}{c}\text { Fl. úmida } \\
\text { vegetal } \\
\text { temperada } \\
\text { basal }\end{array}$} & $\begin{array}{c}\text { Fl. úmida/Fl. } \\
\text { m. úmida } \\
\text { temperada } \\
\text { basal }\end{array}$ & $\begin{array}{c}\text { Fl. muito úmida } \\
\text { /Fl. úmida } \\
\text { temperada basal }\end{array}$ & $\begin{array}{c}\text { Fl. muito } \\
\text { úmida } \\
\text { temperada } \\
\text { basal }\end{array}$ & $\begin{array}{c}\text { Fl. úmida } \\
\text { subtrop. } \\
\text { basal }\end{array}$ & $\begin{array}{c}\text { Fl. muito } \\
\text { úmidal. } \\
\text { ubtropical } \\
\text { basal }\end{array}$ & $\begin{array}{c}\text { Fl. muito } \\
\text { úmida/Fl. } \\
\text { úmida } \\
\text { subtrop. } \\
\text { montana baixa }\end{array}$ & $\begin{array}{c}\text { Fl. úmida } \\
\text { subtrop. } \\
\text { montana } \\
\text { baixa }\end{array}$ \\
\hline SAV-E & 100,0 & 0,0 & 0,0 & 0,0 & 0,0 & 0,0 & 0,0 & 0,0 \\
EST & 78,7 & 8,0 & 11,5 & 1,8 & 0,0 & 0,0 & 0,0 & 0,0 \\
AFP & 100,0 & 0,0 & 0,0 & 0,0 & 0,0 & 0,0 & 0,0 & 0,0 \\
FES & 98,1 & 0,4 & 0,0 & 1,4 & 0,0 & 0,0 & 0,0 & 0,0 \\
FED & 55,1 & 3,1 & 30,2 & 0,2 & 1,4 & 8,9 & 0,9 & 0,1 \\
EST/FE & 65,7 & 0,0 & 34,3 & 0,0 & 0,0 & 0,0 & 0,0 & 0,0 \\
FOM & 47,4 & 27,9 & 12,3 & 5,2 & 1,2 & 4,0 & 1,1 & 0,9 \\
FOD & 100,0 & 0,0 & 0,0 & 0,0 & 0,0 & 0,0 & 0,0 & 0,0 \\
\hline
\end{tabular}

Em que: SAV-E: Savana Estépica; EST: Estepe; AFP: Áreas de Formações Pioneiras; FES: Floresta Estacional Semidecidual; FED: Floresta Estacional Decidual; EST/FE: Estepe/Floresta Estacional; FOM: Floresta Ombrófila Mista; FOD: Floresta Ombrófila Densa; Fl.: Floresta;

\section{CONCLUSÃO}

O estado mostrou biotemperaturas médias anuais de um clima tipicamente subtropical a temperado de 13,7 a $19,8^{\circ} \mathrm{C}$. O índice pluviométrico típico resultou em oito zonas de vida com florestas úmidas a muito úmidas.

Amplas regiões de Estepe, do Pampa gaúcho, coincidiram com a zona de vida floresta úmida temperada basal, de maior ocorrência no estado.

O Rio Grande do Sul mostrou-se um estado com altitudes moderadas a baixas, o que refletiu em pisos altitudinais basal em sua maioria, com alguma ocorrência de pisos montano baixo na região do Planalto Meridional.

\section{REFERÊNCIAS}

ALVARES, C. A. et al. Köppen's climate classification map for Brazil. Meteorologische Zeitschrift, Berlin, v. 22, n. 6, p. 711-728, 2014.

ALVARES, C. A. et al. Modeling monthly mean air temperature for Brazil. Theoretical Applied Climatology, Wien, v. 113, p. 407-427, 2013.

AYOADE, J. O. Introdução à climatologia para os trópicos. 9. ed. Rio de Janeiro: Bertrand Brasil, 2003. BECKER, E. L. S.; NUNES, M. O. Relevo do Rio Grande do Sul, Brasil, e sua representação em maquete.

Revista Percurso, Maringá, v. 4, n. 2, p. 113-132, 2012.

BRITTO, F. P. Distribuição espaço-temporal da precipitação pluvial no estado do Rio Grande do Sul. 2004. 65 f. Dissertação (Mestrado) - Universidade Federal de Santa Catarina, Florianópolis, 2004.

BRITTO, F. P.; BARLETTA, R.; MENDONÇA, M. Variabilidade espacial e temporal da precipitação pluvial no Rio Grande do Sul: influência do fenômeno El Niño oscilação sul. Revista Brasileira de Climatologia, Curitiba, v. 3/4, p. 37-48, 2008.

BURIOL, G. A. et al. Clima e vegetação natural do estado do Rio Grande do Sul segundo o diagrama climático de Walter e Lieth. Ciência Florestal, Santa Maria, v. 17, n. 2, p. 91-100, abr.jun. 2007. 
HOLDRIDGE, L. R. Life zone ecology. San José: Instituto Interamericano de Cooperación para la Agricultura, 2000.

IBGE. Anuário estatístico do Brasil. 2011. Rio de Janeiro: IBGE, 2011. v. 71.

IBGE. Manual técnico da vegetação brasileira. 2. ed. Rio de Janeiro: IBGE, 2012.

IBGE. Mapa de biomas do Brasil: primeira aproximação. 2004. Disponível em: <http://www.ibge.gov.br/ home/presidencia/noticias/21052004biomashtml.shtm> Acesso em: 13 out. 2016.

IBGE. Shape de vegetação. 2006. Disponível em: <ftp://geoftp.ibge.gov.br/mapas_tematicos/mapas_murais/shapes/vegetacao/>. Acesso em: 10 out. 2016.

KUINCHTNER, A.; BURIOL, G. A. Clima do estado do Rio Grande do Sul segundo a classificação climática de Köppen e Thornthwaite. Disciplinarum Scientia, Série: Ciências Exatas, Santa Maria, v. 2, n. 1, p. 171-182, 2001.

MIRANDA, E. E. de (Coord.). Brasil em relevo. Campinas: Embrapa Monitoramento por Satélite, 2005. Disponível em: <http://www.relevobr.cnpm.embrapa.br>. Acesso em: 14 fev. 2017.

NÓBREGA, R. S. Um pensamento crítico sobre classificações climáticas: de Köppen até Strahler. Revista Brasileira de Geografia Física, Recife, v. 3 p. 18-22, 2010.

OMETTO, J. C. Bioclimatologia vegetal. São Paulo: Agronômica Ceres, 1981.

RIO GRANDE DO SUL. Atlas socioeconômico do Rio Grande do Sul. 2. ed. rev. e ampl. Porto Alegre: SCP, 2002.

ROSSATO, M. S. Os climas do Rio Grande do Sul: variabilidade, tendências e tipologia. 2011. $240 \mathrm{f}$. Tese (Doutorado em Geografia) - Universidade Federal do Rio Grande do Sul, Porto Alegre, 2011.

SOARES, R. V.; BATISTA, A. C.; TETTO, A. F. Meteorologia e climatologia florestal. Curitiba: [s. n.], 2015. $215 \mathrm{p}$.

SOTÉRIO, P. W.; PEDROLlO, M. C.; ANDRIOTTI, J. L. Mapa de isoietas do Rio Grande do Sul. In: CONGRESSO BRASILEIRO DE RECURSOS HÍDRICOS, 16., João Pessoa. Anais... João Pessoa: [s. n.], 2005. p. 1-14.

TRES, A. Classificação climática para o Brasil segundo as zonas de vida de Holdridge. $2016.89 \mathrm{f}$. Dissertação (Mestrado em Engenharia Florestal) - Universidade Federal do Paraná, Curitiba, 2016.

TRES, A. et al. Classificação do estado do Mato Grosso segundo sistema de zonas de vida de Holdridge. Enciclopédia Biosfera, Goiânia, v. 13, n. 23, p. 329-342, 2016. 